\title{
Socio-psychological Aspects of Animal Therapy in Treating Children Suffering From Forms of Dysontogenesis
}

\begin{abstract}
Anastasia V. Nikolskaya
Moscow State University, Moscow, Russia

Positive and negative aspects of animal therapy using are discussed. Research of 30 case studies is displayed that pet therapy is a good therapeutic tool in approximately $60 \%$ of cases. To diagnose possible problems in families which have got a dog as a "therapist" for the child suffering from some or other form of dysontogenesis, the author suggests theoretical model of human-animal relationships. This model includes definition of heterospecific group, necessary condition of its creation and sufficient condition of its existing, types of relationships in heterospecific group, psychological phenomena arising in such group, and dynamics of heterospecific group functioning. The methods most relevant to research of heterospecific groups and correction of infringements in these groups are described. For a diagnostic basis, the following classification has been accepted: (1) infringements from the animal; and (2) infringements from the person. Correction of infringement for the purpose of restoring stability in the group is shortly described.

Keywords: dysontogenesis, undirected animal therapy, motivation of human behaviour, theoretical model of human-animal relationships, psychological phenomena of trust, attachment, and rules in a heterospecific group, methods of heterospecific communication
\end{abstract}

\section{Introduction}

Families typically adopt a pet at a child's request, or in the hope that the pet will have an impact on the child's behavior. Undoubtedly, all parents hope that interaction with a pet will have a positive effect on the child, and the child-pet relationship will provide therapeutic benefits.

The therapeutic benefits may be psychological, psychotherapeutic, or rehabilitative, leading to increased self-confidence and improved communications. Moreover, pet therapy can be undirected, during which children interact with pets in the home, or directed, in which therapy is conducted within the framework of a specific program. The text that follows will discuss the effectiveness of undirected pet therapy.

As a rule, interaction with an animal has a positive or neutral effect, unless the child has the pet and its care imposed from above. However, this positive or neutral impact is typically observed when both child and animal fall within the developmental norm. But how is the relationship altered when either the child or animal deviates from the developmental norm?

First of all, not every pet is capable of acting as a "psychotherapist". The animal's capacity depends on both individual and breed characteristics. Most importantly, the animal should have a stable temperament and lack aggression. Unfortunately, the author has observed many animals suffering neuroses arising from lengthy 
and inappropriate interactions with humans, and the animal needs a respite from interaction. A child's persistence can trigger fear or aggression even in quiet and nonaggressive animals.

Secondly, children, particularly those of preschool age, perceive a pet as a playmate and anthropomorphize the animal. In such cases, experts must explain the type of behavior and typical of the species in a manner comprehensible to the child. Thirdly, if we are discussing various forms of dysontogenesis in children, we must take into consideration the varying behavioral and psychological characteristics of each child and select animals with the temperament and skills appropriate for communicating with the child.

For example, a child suffering from ADHD (attention deficit hyperactivity disorder) will irritate a passive or calm animal, possibly triggering fear or aggression. Alternatively, a very active animal may trigger anxiety and irritation in a child with autism.

In the case of children suffering from cerebral spastic infantile paralysis and/or mental retardation, playing with a cat or a dog promotes mobilization of impellent activity, development of motility, and coordination of movements. For example, a dog holds an object in its mouth and gives it to the child. A mature, trained animal will be able to judge when to continue holding the object and when to release the object. In such cases, the dog should be tested in order to determine its level of motivation to fight for status; in similar exercises, the dog should not demonstrate dominant behavior or aggression.

Pet therapy is also used in the rehabilitation of children with various types of mental retardation. For example, a pet can reduce lethargy and anxiety, and help the child achieve some measure of independence. In this case, we should take into consideration the temperament of the animal, as an overly calm animal will not stimulate a lethargic child.

Thus, therapeutic exercises are less important for the child than the psychological impact arising from interaction with the animal, which is the most important aspect of pet therapy.

Interaction with a confident, well-adjusted pet can alleviate stress and imbue positive emotions, and once positive emotions arise, the child's cognitive activity begins to develop. Children perceive, remember, compare, analyze, and apply new experiences to similar situations. Moreover, children develop empathy and understanding based on their own experience. However, the animal with whom the child communicates cannot guarantee the child's emotional well-being. The personal characteristics of the child and the animal may be incompatible. To prevent such incompatibility, families should work closely with a psychologist who can make recommendations regarding the type of animal that is most appropriate and likely to result in a "working team". Only through an appropriate pairing will the child develop emotional well-being that will be reflected in an increasingly positive view of himself/herself and the world around him/her.

However, there is one more important circumstance that must be considered by a specialist, which is the atmosphere that predominates within the family. Later in this piece, we will look at four case studies that illustrate how significantly the family environment influences the interaction between child and animal.

Furthermore, we will describe research conducted in special education classes at Moscow Municipal School Number 4. The research included 30 children with various forms of dysontogenesis: six children with moronity-stage oligophrenia, three children with cerebral spastic infantile paralysis, eight children with antisocial personality disorder, five children with autism (Asperger syndrome), and eight mentally retarded children.

During conversations with the children and their parents, we asked the subjects at 6-12 years old to draw their families, as represented by circles designating the child and each family member, including pets, on an A4 
sheet of paper, and talk about the animal, including habits and behavior. The following examples demonstrate various forms of dysontogenesis and how effective undirected pet therapy proved to be in each case.

\section{Moronity-Stage Oligophrenia and Mental Retardation}

\section{Case Study 1: OL}

$\mathrm{OL}$ is a 12-year-old female with moronity-stage oligophrenia. The subject's emotional background is relatively stable. There is a general decrease in the cerebral cortex tone that is necessary for any active mental activity. This deficit is expressed through abrupt shifts from excessive activity to pronounced exhaustion. Fluctuation in working capacity and mental activity is marked. OL has no difficulties in social interaction.

The family unit includes a father, mother, and elder brother (aged 20, normal development ontogenesis). No pathologies in mental development were observed in the family until OL's birth. The family environment is harmonious, and the parents are active hikers. They continued this hobby after the birth of their first child and took the son hiking as well. Following OL's birth relationships in the family remained relatively unchanged, although the sick child received considerable attention. The family actively searched for ways to help OL develop. She received medical support and participated in a wide range of developmental activities with experts as well as with other adults and children. The pace was grueling for the child, and she sometimes fell asleep on her feet, but the family's example led her to carry on. The child is well cared for and loved. Her wishes are respected, but she is not spoiled. The brother often walks with her and is not ashamed of his sister. The child is not hyper-mothered.

The parents reviewed scientific and educational literature suggesting that dogs promote socialization and development in children suffering from oligophrenia, and consequently obtained a puppy, a 2-year-old female dog named Alma.

The appearance of the puppy was a surprise for OL. Two years later, the girl describes with pleasure how she did not expect to receive a puppy and what pleasurable emotions she has experienced. OL delights in caring for Alma, playing with her, and walking her. The family continues to hike and the dog is taken along. Alma is not aggressive, exhibits no behavioral problems, intelligent, and patient with OL's excessively emotional demonstrations of love. The dog has no difficulties in social interaction and enjoys being walked. When it is time to walk, Alma brings her leash to one of the parents. In the absence of the parents or brother, the dog does not ask OL to walk. The dog behaves well in the street, and does not bark at home. When Alma wants to eat, she "calls" the parents or the brother. "All of her facial expressions tell us what she wants; it is not difficult to guess".

The parents believe that the dog sees OL as a puppy, "All children play tricks on their parents and you should see what OL does to Alma!". When OL cries or is tired, the dog approaches her, lays her muzzle on OL's knees, looks her in the face, and "worries" or "sympathizes" if she does not know how to help.

Everyone considers the dog a member of the family. The father says:

For a family in which there is a sick child, a dog is like a doctor, or a pillow that will absorb all tears and disappointments, both from the child and his parents. Certainly, the dog bears a heavy emotional burden in our family. She is so understanding and patient that we have no right not to care for her or love her.

OL's family drawing is shown in Figure 1. 

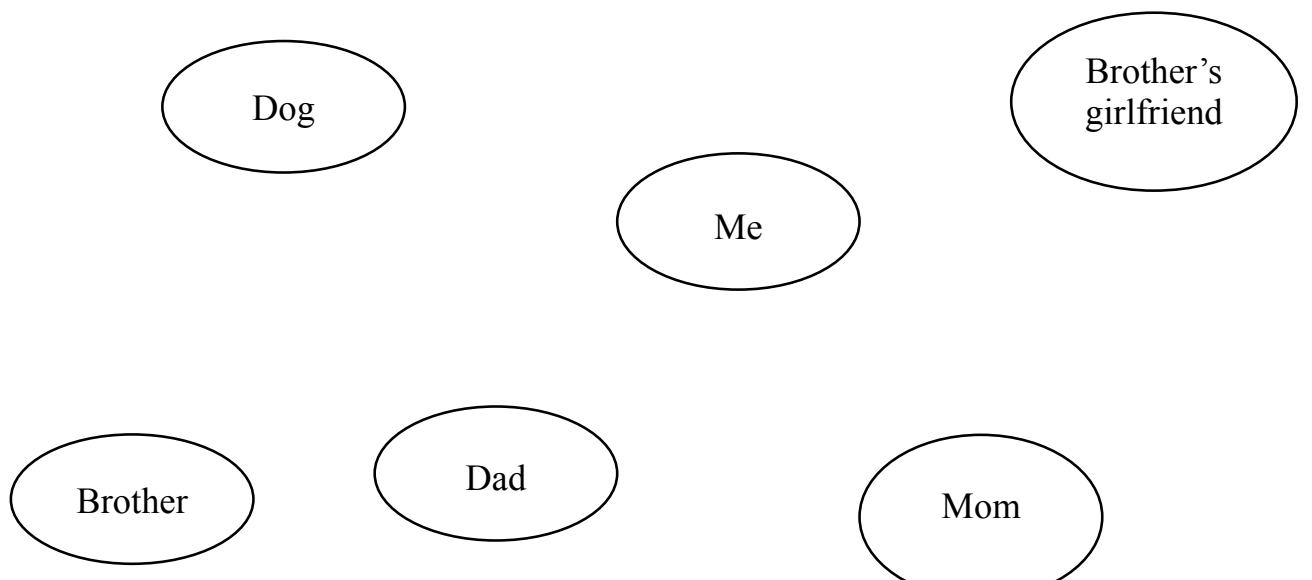

Figure 1. OL's family drawing.

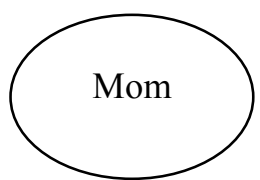

In the drawing in Figure 1, it is clear that the parents, the brother, and the dog are included in the family structure. OL takes a central place. All members of the family "revolve" around the girl and she feels this.

Relations within the family are very harmonious. These relations extend to each family member, including the dog. The labrador is relaxed and therefore is able to provide a therapeutic function. In this case, it is clear that undirected pet therapy offers positive therapeutic effects for OL.

\section{Case Study 2: NT}

NT, an 11-year-old female, suffers from moronity-stage oligophrenia.

NT is emotionally unstable, with a short attention span and an inability to control emotions that leads to acting out. The girl exhibits difficulty in self-control, an inability to suppress emotional displays, and insufficient consideration of her actions. Her emotional volatility often leaves her exhausted.

Affective behavior is replaced by strongly pronounced weariness, and NT may fall asleep at any time. When tired, NT will become capricious, shout, or push other children and fight. Considerable fluctuations in working capacity and all mental activity are marked. NT has serious difficulties in social interaction with children and adults.

The family unit includes a father, mother, and grandmother (the father's mother). No previous pathologies in mental development existed in the family. NT is unable to answer the question: "Who do you love most?".

The family also owns a 4-year-old male Cane Corso (Italian mastiff) named Sprat. The dog joined the family when NT was seven. The father stated that he bought the dog because "my daughter needs to learn to take care of someone". The mother opposed the dog, explaining that she had enough work with NT and a dog is also like a small child. She feared that the responsibility for caring for the dog would fall upon her shoulders. No family members had any previous experience with dogs. The mother cares for the dog but refuses to walk it, because she cannot control the animal who is aggressive toward other dogs.

The family considers the dog to be aggressive, but according to the father's words "the dog should behave this way, it is normal". The grandmother opposes the dog's presence, believing that the parents waste time that should be devoted to their daughter on caring for the dog.

The dog established its own rules from the very beginning, biting NT's feet and the grandmother, growling at anyone who passes, and sleeping wherever it wants. Any attempts to move the dog result in growling and even biting. 
NT is fearful and tries to avoid the dog, refusing to touch him. The dog likes to play, but constantly tries to bite, scratch, and intimidate. NT perceives the dog only as another presence in the house.

The father finds the dog an irritant and attempts to avoid interaction. NT often complains about the dog to her father who admonishes her to show courage. The father believes that it is better for NT to become accustomed to the idea that the world does not revolve around her, and there are others who need care more.

The dog is not well-adapted to the urban environment. During walks Sprat fights with dogs of all breeds, ages, and genders. Consequently, he makes frequent visits to the vet. Sprat constantly barks at passersby, and frightens small children by growling and jumping on them. The dog's aggressive behavior began at the age of four months.

At home, Sprat barks constantly when he is not eating or sleeping. He has a bed in the corner, but he does not sleep there. He sleeps where he wants and any attempt to move him is dangerous.

NT is afraid of the dog, and negative emotional outbursts have become more frequent. According to her parents, she behaves very badly at home, crying, whining, and refusing to do her homework or study. The parents state that they are doing their best for her, taking all measures possible to accommodate the limitations imposed by her illness. They state that they obtained the dog because they were told by a doctor that an animal would be helpful in socialization.

The father's emotional story demonstrates clearly that the animal is not addressing the child's problems, but rather exacerbating the negative dynamic in the family by its very presence. Constant barking in the presence of family members suggests a serious neurotic disorder (Nikolskaya, 2007; Horwitz \& Mills, 2009, 2005; Overall, 2005) and the dogs' behavior demands correction, with participation by all family members. However, the parents have failed to discipline the dog even as they expect the dog to help the child adapt to the world around her.

Asked whether it would not be better to return the dog to the breeder, given the lack of the anticipated result, not to mention aggravation of the existing problem, the father said, "He should be in the house. Everyone has a difficult character. Sometimes, NT is intolerable, but we cannot give her back".

Consultant: But NT is afraid of the dog, and his presence exacerbates her condition.

Father: We do all our best for our child, she suffers from oligophrenia and this diagnosis is permanent; she is going to have to learn how to adjust. Of course, nerves get the best of me sometimes.

Consultant: And how do you cope when nerves get the best of you.

Father: I shout... and I go out to walk the dog even though I do not enjoy it.

Consultant: You do not like to walk the dog, do you? And who walks him when you do not?

Father: My wife and NT.

Consultant: But she is afraid to walk the dog, he is aggressive with other dogs and she has difficulty controlling him. Every situation is traumatic for NT. Do you think about that?

Father: No, no, no, you are not right. Do not cause trouble. The dog is good for everybody.

Consultant: OK, what concrete advantage does the dog offer the family, or at least NT?

Father: I do not want to talk about that. I am here to address a problem with my child. I have heard that pet therapy is very useful because a pet promotes socialization.

Consultant: But socialization means helping the child learn to function fully and properly in society. How does a conflict-ridden relationship with the dog promote socialization?

Father: She will learn to face adversity. Society does not accept children like NT, and she has to fight.

Consultant: How should she fight?

Father: She has to stand up for herself and for her rights. She has to be strong.

Consultant: But how will she be strong if she's is afraid of the dog and tries to avoid contact with him, and if that is 
impossible acts out aggressively toward the family, including you.

Father: I believe my daughter is learning to cope with difficulties this way. She is sick and society will not accept her. It is necessary to fight!

Consultant: OK. In your opinion, who is the leader in your family, who can control the dog's behavior?

Father: I do not know who his master is. Most likely, Sprat is the master of the house.

Consultant: With the dog holding such a position in the family, contact with the animal is difficult, especially for NT. But, anyway, if you do not want to get rid of the dog, he should not be aggressive toward NT, but protect the child as he would a puppy.

Father: Sprat should love the puppy, but he does not love anyone. This means there is no puppy in our house.

NT's drawing of her family is shown in Figure 2.
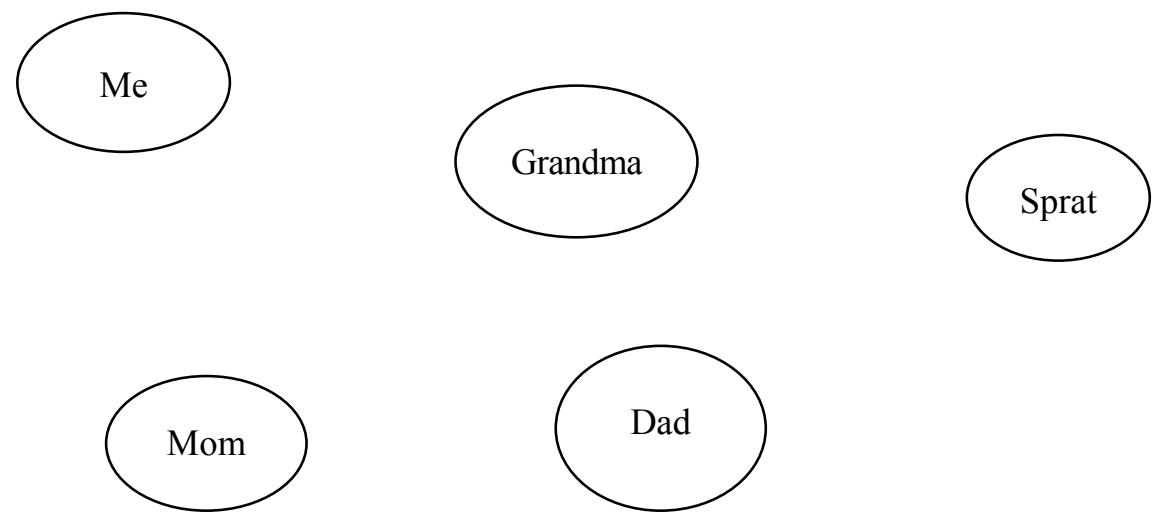

Figure 2. NT's drawing of her family.

The drawing makes it clear that the family consists of isolated elements which exist at a distance from one another.

Disharmony within the family does not help NT adapt to society. On the contrary, relations within the family aggravate the girl's difficulties and the dog's presence makes things worse.

NT is afraid of the dog and expresses her fear, insecurity, and rage through deviant behaviour. She is unable to cope adequately with her repressed rage and insecurity.

In this case, undirected pet therapy has clearly not led to a positive therapeutic effect.

\section{Case Study 3: SD}

$\mathrm{SD}$, a 10-year-old mentally retarded male, was born with hypoxia. His emotional background is unstable, and expressed through constant mood swings:

(1) Sometimes, the boy is euphoric with heightened emotion and verbal activity. At other times, the child will not engage in any activity without constant stimulation from the psychologist or teacher. While doing schoolwork, he repeatedly asks the teacher whether he is completing his assignments correctly;

(2) Sometimes, he is in a neurotic state, and he suffers from depression. He exhibits heightened anxiety, sensitivity, and vindictiveness. He remembers everyone who has offended him and is verbally aggressive toward perceived offenders.

His behavior is not always appropriate to the situation. Decreasing cognitive function is marked. He quickly loses interest, refuses to engage in any voluntary activity, and has difficulty in resuming activity.

SD has difficulties in social interaction: He is often silent, shy, and inactive, but he can become excited, expressing displeasure through conflict and verbal aggression. He is disliked by classmates and has no friends. 
His family includes his father, mother, and paternal grandmother. No pathologies in mental development existed in SD's family prior to his birth.

In answer to the question "Who do you love the most", he answers "I love everyone".

The family owns a 3-year-old poodle named Lord who joined the family when SD was 7. The dog was purchased by the boy's mother; according to the father, "She loves animals very much and believes that it is essential to have an animal, especially a dog, in the house. We take care of them, and teach our son to care for the weak". The family is experienced in taking care of dogs, and all family dogs were obtained by the mother. They included:

(1) The first dog was a male named Dachshund. He lived with the family for five years and was the alpha dog in the family. Everybody "was subordinated to his whims". He bit the owners and SD, pushed SD, fought with other dogs, and slept where he wanted. "But he was such a lovely tyrant!" When SD was four years old, the dog disappeared from the family's summer home. The mother was extremely upset and got another dog at once. SD exhibited no concern, probably because he did not understand what had happened;

(2) The second dog was a male named German shepherd purchased by the mother, because he seemed "so defenseless" to her, but appeared to be a badly behaved dog. He defecated and urinated throughout the house, and bit anyone attempting to play with him, especially SD. "It was impossible to walk him, as he constantly wanted to fight". He lived with the family for three years, until he was hit by a car. SD was extremely upset by the incident, after which he experienced nightmares and developed a fear of crossing roads. Thereafter, he would only cross when his parents took him by the hand;

(3) The third dog is a male poodle who has lived with the family for three years. The dog frightens SD, bites his ankles, does not allow the child to touch his toys, and destroys the child's books. Initially SD was very excited about the new dog, but he became increasingly wary as the dog's character was revealed and began to avoid interaction. He does not play with the dog and walks him very rarely, and then only with his mother.

Mother said,

I see that SD is wary of the poodle and does not touch him or disturb him. However, Lord does not seem eager to interact with SD either. Sometimes when SD is ready to play with him or feed him, he bites or growls, frightening the boy.

The dog likes to play, but constantly tries to bite, scratch, and intimidate by growling. In the street, the dog behaves badly, is aggressive toward other dogs (any breed, sex, or age), barks at passersby, and frightens small children by growling. The dog's sleeps on or near the sofa, and SD avoids the dog's sleeping area as he is afraid of Lord.

The mother loves the dog and takes care of him, while the father views the dog either neutrally or with irritation, constantly reproaching his wife for buying an awful dog. He does not want to walk the dog, and believes Lord is crazy. He makes comments, such as "SD, kick his ass".

The dog does not play with the father and growls at him, but does not bite. Occasionally, the dog sleeps near the father while he watches TV. The father is indifferent, and does not show the dog affection. Should SD appear, the dog growls without lifting its muzzle. If the mother approaches, the dog shows pleasure, and the grandmother is ignored. The grandmother has never touched or walked the dog, and in turn, the dog has never shown aggression toward her or initiated contact.

When asked "Who do you love the most in your family", SD answered "I love everyone".

And when he is asked "Even Lord?", he will answer "Lord too". 
The family considers the dog to be aggressive, although the mother thinks this is normal for a male dog. The father and SD agree, while the grandmother believes that they have turned a small dog into a monster. She believes that the dog will do the boy no good, but rather expose him to constant stress.

SD's family drawing is shown in Figure 3.
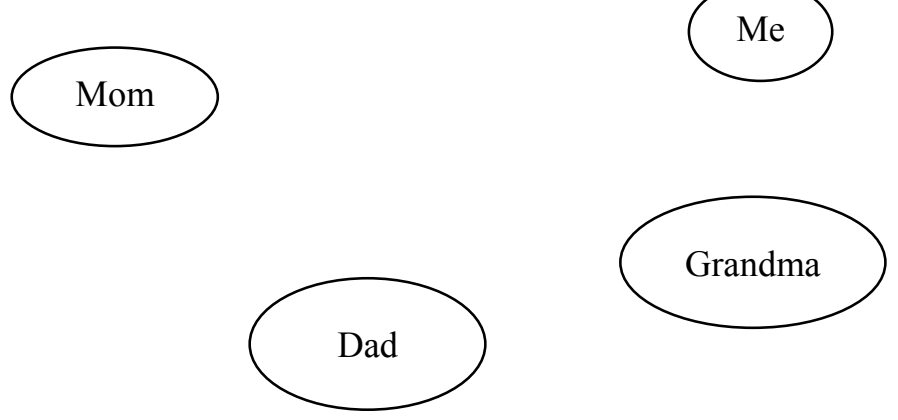

Figure 3. SD's family drawing.

We can see in the drawing that the family consists of isolated elements, while the dog is not present in the drawing. Relationships in the family are not warm or friendly. The relationship between family members aggravates SD's condition and the dog's behavior. With such a dynamic and the absence of mutual support, the dog is desperately trying to understand his status within the family. The owners provide the dog with no support, making him neurotic, and similarly the dog offers no therapeutic benefit to the boy. SD fears the dog, and as a result, the dog does not contribute to increased self-assurance. The child is unable to process his repressed aggression adequately, i.e., the dog not only fails to carry out a therapeutic function, but also exacerbates the child's feelings of insecurity and loneliness.

Notable is the fact that all of the dogs were brought into the home by the mother. Each was an aggressive and uncontrollable male. Consider that relations in the family are not warm, and adult members of the family provide to support or acceptance to each other. Moreover, the child suffers from developmental issues. The woman is most likely lonely and compensating with the dogs. In this case, the dog's gender is relevant. The aggressive dog, who in the mother's opinion is acting appropriately, is unconsciously perceived to be a defender and, in part, faithful admirer. The fact that all the dogs have been aggressive toward the child has not stopped the mother from obtaining male dogs.

Let us consider a case in which a dog lives in a home with a mentally retarded child, but in a more harmonious family environment.

\section{Case Study 4: MN}

MN, a 10-year-old mentally retarded female, was born with hypoxia. The first month of her life was characterized by anxiety, emotional instability, and insomnia, the strengthening of congenital reflexes was marked. Her emotional background is stable, and her behavior is typically appropriate to the situation. However, her mental function is diminished and she has certain speech difficulties that prevent her from communicating with other children.

MN has no obvious difficulties in communicating with her schoolmates. Her classmates accept her, but she is confused in conversation and typically tries to avoid conversation, remaining silent and smiling. She has no friends, but she is on good terms with everyone. She is a quiet and hardworking girl. 
MN's family consists of her father, mother, 20-year-old sister, and 5-year-old sister, both of whom are developmentally normal. Prior to MN's birth, there were no pathologies in mental development present in the family.

There are friendly, close relations between all members of the family. The girl loves her mother and sisters very much.

The family has a 3-year-old female golden retriever named Ulya. The father bought the dog for the elder sister since she is studying veterinary science. MN was seven years old when the dog joined the family. Prior to Ulya's arrival, the family had no experience with dogs.

MN plays with and talks to the dog, walking her in the afternoon. She does not hesitate to speak to the dog, despite her speech difficulties, saying that the dog understands her no matter what she says. Everyone in the family believes that buying Ulya was the right decision. Ulya appears to listen to MN and allows her to speak. The family considers it beneficial for MN to have someone with whom she can speak freely and improve her pronunciation.

MN perceives the dog as a younger member of the family, "I take care of her myself, I play with her, I feed her". The dog likes to play, and does not bite or scratch.

The dog plays enthusiastically, often presenting a ball to play fetch. The sisters play a game that involves jumping from sofa to sofa with the dog behind them. If $\mathrm{MN}$ or anyone else pushes the dog away, Ulya returns to her corner looking sad.

In the street, the dog behaves well and barks rarely. When she wishes to be fed, she communicates with the mother. The dog's bed is in the hallway. No one excepts the youngest sister disturbs the dog in her bed, and Ulya has never banished the child.

The mother is the dog's owner, and Ulya obeys her. She is more engaged with Ulya than any other family member.

The father is neutral toward the dog. Ulya does not play with him or react to his commands. Sometimes, when he watches TV, she sits with her muzzle on his knee and he pats her. She sleeps at his feet.

The eldest sister has taken only sporadic interest in the dog, but has made some attempts at training. Ulya "was interested in training at the beginning, but usually gets tired or bored and returns to her bed, ignoring the sister's attempts to call her back".

MN perceives the dog as a friend. The family does not consider their dog aggressive, even stating that "she is too kind".

MN's family drawing is shown in Figure 4.
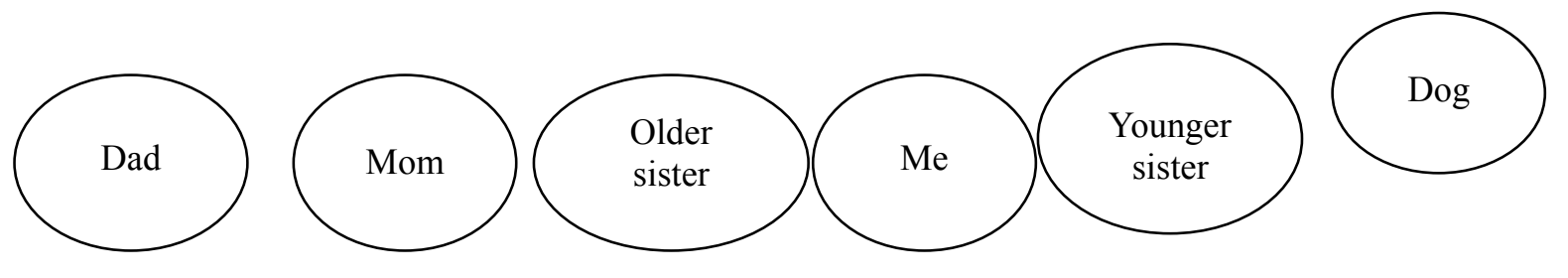

Figure 4. MN's family drawing.

We can see that the dog is perceived as the youngest member of the family. Everybody likes Ulya and takes care of her.

This is yet another example of how the family's relationship with each other and the dog influences the 
character of each family member, including the dog, and renders a therapeutic effect.

Thus, we have shown in four case studies, in which the subjects suffered from the same disorder but family environments differed significantly, that relationships between the disabled child and an animal developed in radically different ways. In Cases 1 and 4, we see therapeutic success and a positive result from interaction between the animal and the child, while in Cases 2 and 3 positive therapeutic effect was not only absent, but the subject was irreparably harmed through fear of the dog.

In total, pet therapy had a positive impact on children suffering from oligoprenia (six children: two boys and four girls) in five cases and for children suffering from mental retardation (eight children: four boys and four girls) in six cases.

\section{Autism $^{1}$ (Frith, 1991; Rothenmerg, 1977; Grandin, 1988)}

In the course of research, five children (four boys and one girl) suffering from autism (Asperger syndrome) were studied. All of the children occasionally demonstrated unmotivated aggression. Their parents describe the attacks as follows: At such moments, the child becomes extremely vicious, fails to react to speech, makes stereotypic movements, shouts and sometimes bites. In each of these families, the dog was able to sense the approach of an attack. Independent of size, gender, or breed, each dog would howl, turn, bite its tail, rush between rooms, or hide 3-5 hours prior to the onset of such an attack.

Parents of these children describe the relationship between the child and dog in similar terms:

AT does not take any initiative to look after the dog, or play with it or walk it.

SI does not pay attention to the dog at all.

AN does not notice the dog, and is uninterested in it.

SB does not notice the dog or react to it.

IK and the dog simply coexist in the same space.

It is interesting that the dogs do not react to the children, do not initiate contact or play, and do not expect any reaction from the children. Despite these facts, three of the five children (boys) studied drew their families including the dog but excluding themselves

For example, AT's (male, eight years old) family drawing is shown in Figure 5, and SI's (female, 11 years old) family drawing is shown in Figure 6.

As shown in Figures 5 and 6, one boy did not include the dog in his drawing, but one girl included both herself and the dog.

Evidence suggests that dog possesses diagnostic capabilities, giving parents timely warnings of an imminent attack. This aids the parents in reacting and implementing the necessary safety measures.
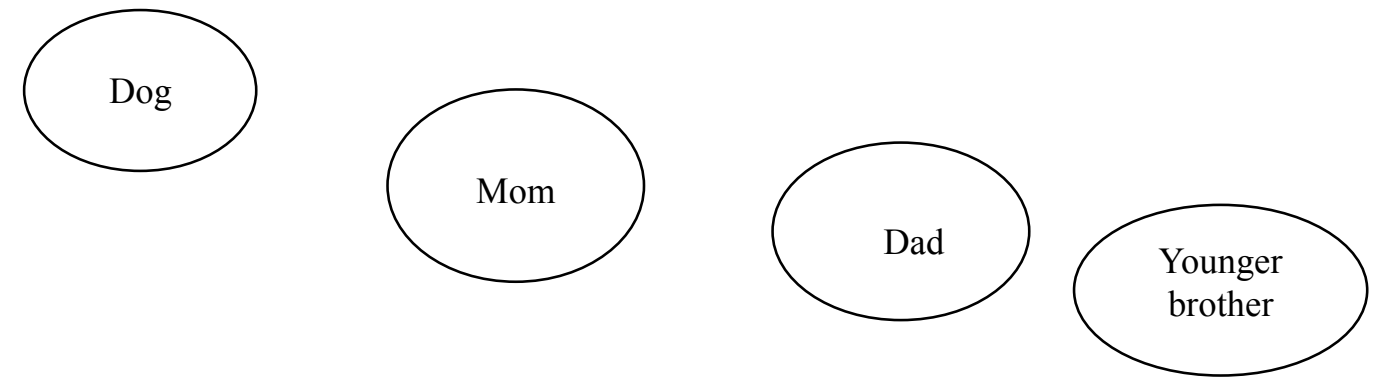

Figure 5. AT's family drawing.

\footnotetext{
1 There is considerable literature devoted to autism and Asperger syndrome.
} 

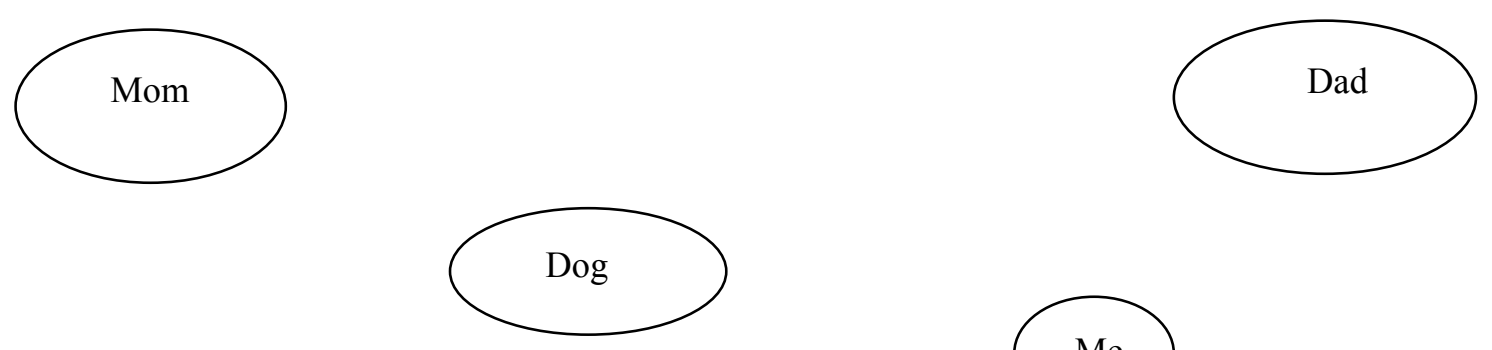

$\mathrm{Me}$

Figure 6. SI's family drawing.

In this case, it is difficult to determine the positive impact of undirected pet therapy since the impact is reduced to preventing an attack. However, the presence of the dog in four of the five drawings suggests that the child includes the dog in his/her internal world even if this is not demonstrated through behavior. Finally, it is necessary to note that all dogs react to the approach of an attack by exhibiting fear and excitement. These families have kept their pets, and no child has been bitten. However, a fearful dog can behave aggressively and therefore parents should keep the child and dog separated from one another in such circumstances.

Pet therapy appears to have been successful in four of five cases.

\section{Antisocial Personality Disorder (Millon, 1981)}

Eight children (boys) with dogs were studied. During interviews with the children and their parents, all parents complained about flare-ups with aggression, obstinacy, and negativity. Affective explosions usually have an asthenic outcome with crying. The emotional background of such children is unstable. Often, affective negative explosions are accompanied by impulsive outbursts displayed in the form of unexpected and strong shouting, jumping, and throwing objects followed by euphoric shifts in mood and relaxation. The affective reactions do not correspond to environmental influences or stimuli. The children are irritable and incapable of delayed gratification, and demand a constant change of impressions.

The pet-child relationship is described as follows:

I constantly watch to see that VK has not harmed the dog, especially when VK having one of his attacks.

When the dog was a puppy he constantly tried to establish closer contact with LF, but LF pushed him away. But now, LF has learned to be accepting of the dog, and they stay near each other. The dog has learned to sense LF's attacks and retreats to his bed before the attack begins.

When SM is in a good mood, he looks after the dog: feeds him, plays with him and walks him. Sometimes, SM hugs the dog enthusiastically and he tries to escape. If he cannot, he begins to growl. If SM does not react, he lightly bites the boy's hand.

BP has been very delighted and immediately began to participate in caring for the puppy. He named the dog, made him a bed, and chose a food bowl. BP expresses emotions very clumsily, he picks up the dog, or pushes him. We did not interfere. Occasionally, the dog whined, then growled and eventually bit BP, which made him cry. His father told him it serves him right for tormenting the dog. Thereafter, BP had no positive interactions with the dog. He ignores him, and may push or hit the puppy.

AR tries to look after the dog: to feed him and play with him, but the dog clearly discourages him from approaching. And as the dog is big (a Rottweiler), AR will not take the risk. AR's attacks irritate the dog, and he may bite the boy if he screams at his mother or grandmother. AR is afraid of him.

Unfortunately, DN cannot play with the dog normally, he plays crazy games, the dog runs away and growls. Then DN becomes angry and throws the dog aside with malicious laughter. He will not touch the dog anymore. 
For example, VK's (male, 10 years old) family drawing is shown in Figure 7.
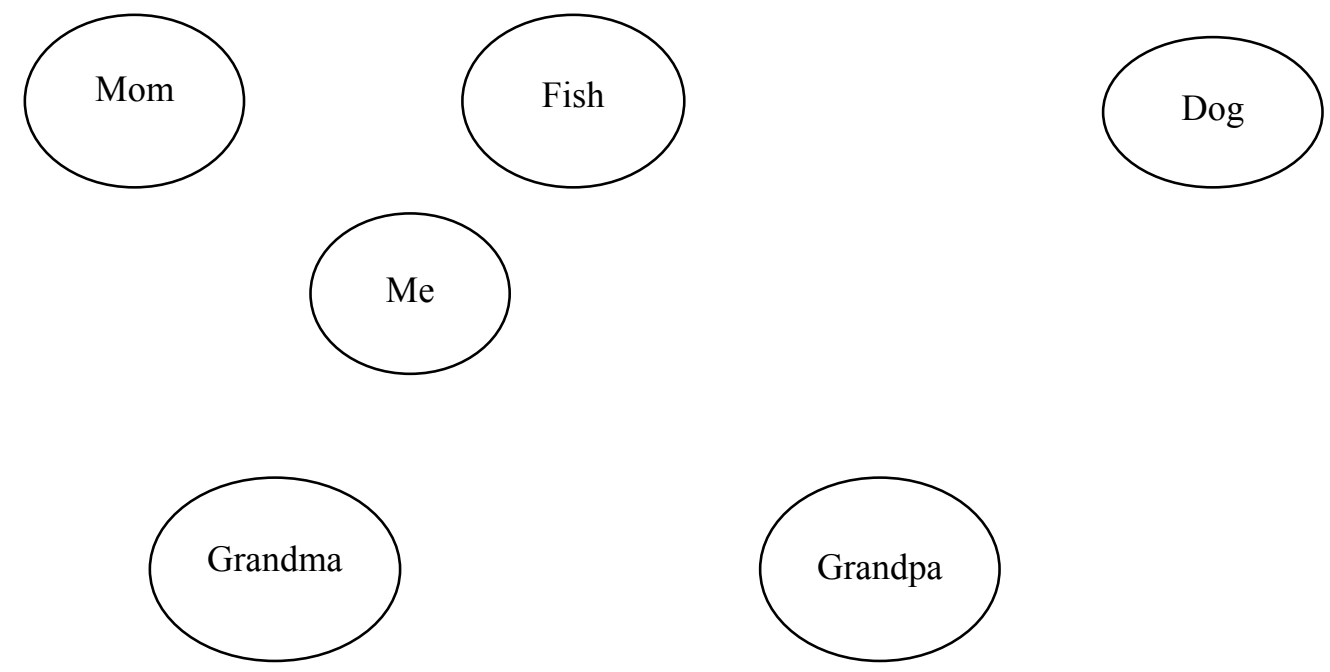

Figure 7. VK's family drawing.

We can see that the dog is included in the family structure, as are the fish, and the fish are even closer to VK than the dog. On the basis of this drawing and his mother's account of his interaction with the dog (a Dachshund), we conclude that the dog has no special value to VK. Although the dog does not play an important role in the boy's life, he nevertheless contributes to VK's socialization through the family's efforts to ensure that VK does no harm to the animal.

BP's (male, eight years old) family drawing is shown in Figure 8.
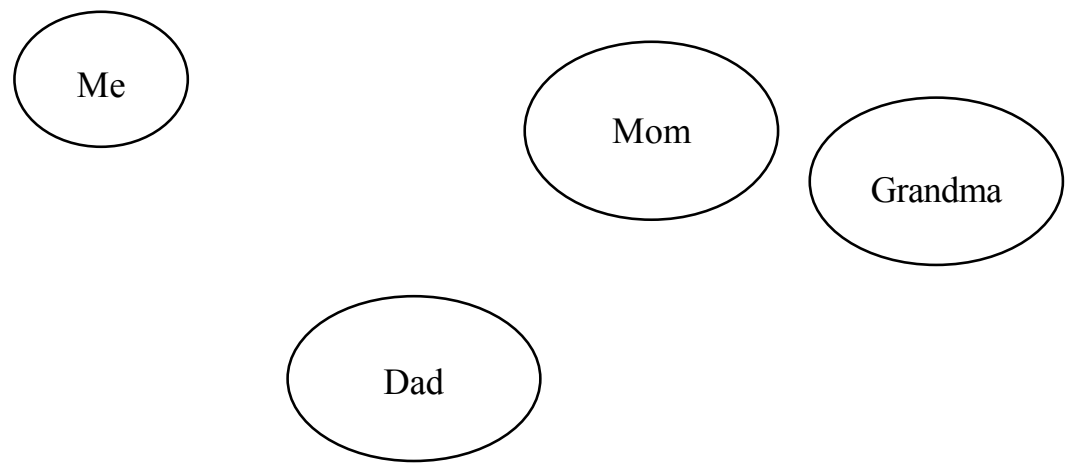

Figure 8. BP's family drawing.

We can see the drawing in Figure 8 that the dog is not included in the family structure. The boy feels lonely. On the basis of the drawing and his mother's story of his interaction with the dog, it is possible to assume that under the present circumstances, the dog (a whippet) does not trust the boy and considers his behavior dangerous and unpredictable. The dog was bought for the child, but the parents "did not interfere in their interaction". The dog has become a burden to the family, and its presence in the home does not promote harmonious relations with the child.

Unfortunately, pet therapy demonstrated a positive impact on only four of the eight cases studied.

We must also note the difficult circumstances for dogs that live with children suffering from antisocial personality disorder. The dogs are either afraid of the children or behave aggressively. As a result, the child 
either becomes fearful or begins to act aggressively toward the animal, demonstrating superiority. Such interactions obviously do not lead to any therapeutic benefit.

\section{Cerebral Spastic Infantile Paralysis}

Three children (one boy and two girls) with dogs were studied. In each case, the parents purchased the dog specifically because they had heard that pet therapy can benefit children suffering from this disorder. Moreover, it has been determined that in addition to the benefits from interaction with any pet, children suffering from this disorder benefit even more significantly from interaction with fluffier and shaggier dogs as they promote muscle relaxation. Interaction with the dogs calms and relaxes the children, and parents were consequently interested in searching for larger and shaggier animals.

Consequently, the children studied owned an old English sheepdog, a St. Bernard, and a Bernese mountain dog.

While all the families involved were searching for a tool to treat the child's disorder, it is notable that two of the families ended up with a new family member.

All the children love their dogs, take care of them, walk them together with their parents, and even attempt to train them. However, attempts at training have met with little success as the children are too tentative to elicit any reaction to their commands. All the dogs are happy to play, although the St. Bernard is more sedentary. The sheepdog and Bernese mountain dog are more active and the children tend to tire first. The dogs recognize the command "tired" and retreat when ordered. The dogs are happy to lie quietly with the children as long as necessary. Two of the dogs tend to react calmly if they are hit by the child's wheelchair. The sheepdog barked at the child in this situation, but the girl demonstrated that she was "sorry" and now the dog reacts to such collisions calmly. The children say of the dogs:

Graf is my best friend. It is healthy for me to be with him.

Tom pushes me in my wheelchair just like my friend Dima, but Dima does not use his nose. He is four years old now, and I have heard that St. Bernards do not live very long. I dream that he will live as long as a person, for 70-80 years.

Dora understands me better than anybody else. She feels sorry for me when I cry. I can talk to her about my dreams and it seems to me that she understands, because sometimes she sighs, as though she knows they are impossible.

In all these cases, pet therapy has yielded significant benefits. Note that two families searched for a dog that would be another member of the family, while one family (owners of the sheepdog) wanted only a tool for treatment. But now the mother says:

We look after AL together, including the dog; difficulties have brought us together and now we (me, my husband, AL, and Graf) are a good team with strong mutual attachment, friendship, mutual understanding, and mutual assistance. And despite my initial ideas about getting a dog, I have accepted him and fallen in love with him.

AL's (female, eight years old) family drawing is shown in Figure 9.

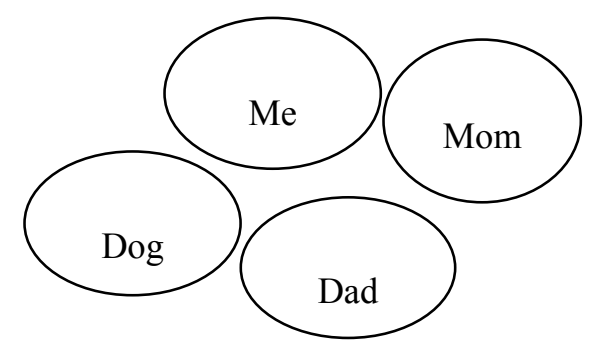

Figure 9. AL's family drawing. 
We can see that the dog is included in the family structure and plays an important role, like the mother and father. All of the family members are closely connected to one another and harmonious relations predominate, including with the dog. The fact that the mother was able to accept was the dog played an important role. Such a favorable environment facilitates therapeutic benefits for AL, and this is "not at the expense of or detriment to the dog" (in the words of the mother). In this case, it is evident that undirected pet therapy has yielded therapeutic benefits not only for AL, but for her parents as well.

\section{Conclusions}

These 30 cases demonstrate that the presence of a dog does not always yield therapeutic benefits. In eight cases (one child of six with oligophrenia; four children of eight with antisocial personality disorder; two children of eight with mental retardation, and one child of five with autism), from the 30 cases studied (approximately 26\%), the presence of a dog negatively influenced family dynamics and did not lead to therapeutic benefit. In each of these cases, it is important to note that disharmony existed between family members prior to the arrival of the dog.

In all of these cases, the dog's behavior was also abnormal. In 18 of the cases studied (60\%), the family relationship was initially harmonious, the dog was successfully introduced into the family and developed a good relationship with the child, yielding a positive therapeutic impact. However, with four of the five autistic children, the dog was successfully assimilated into the family and positively influenced family dynamics, warning parents of imminent behavioral problems. However, it is observed that the positive impact on the child was minimal, and the dog was frequently viewed with indifference by the child. In each of these cases, the dog was able to sense the onset of tantrums. In one case, the dog's fear was so strongly expressed that it led to neurosis with motor stereotypy.

Can we say that pet therapy is a good therapeutic tool? This depends on three aspects that the specialist must take into account when working with families of children suffering from various forms of dysontogenesis:

(1) General family atmosphere;

(2) The compatibility of the child's personal characteristics and characteristics brought on by the disorder with the individual nature and breed characteristics of the dog;

(3) Possible behavioral problems in the dog.

At a minimum, the specialist should be an expert in the fields of family therapy, medical psychology, and small animal behavior. How is this possible? As a consequence, experts in pet therapy consistently decry the lack of clear scientific and methodological data that could help define the most appropriate procedures for pet therapy in specific cases (Grandgeorge, 2011).

First of all, it is necessary to remember that the worlds of both the sick child and the dog are confined to the narrow limits of the family, which consequently plays a huge role in the well-being of all involved. In connection with this factor, we shall discuss modern psychology and its methodological apparatus, attempting to offer a possible theoretical model that specialists may use in the field of undirected pet therapy.

Modern mainstream psychology has approached the postnonclassical stage of development. The main principle of this stage is the ontological approach to researching mentality, which includes a system, structure, and evolution approach. The gnoseological bases of such an approach provide the context for scientific knowledge, informing its humanitarian and ecological value. The methodology of an ontological paradigm 
consists of methodological pluralism, and accordingly psychological methods have been increasingly transformed from quantitative to qualitative (Lebedev, 2010).

One of the general features for all postnonclassical tradition is the rejection of any empirical basis independent of theory, in relation to which it would be possible to compare theoretical designs. Any description of "the empirical world" that is not based on accepted theoretical principles cannot exist at all. But, if researchers rely on the different theoretical bases, then pictures of the reality they describe will be different (for example, researchers in animal psychology, from positions of atomism and anthropomorphism, will treat the same behavior exhibited by the same animal from different bases). Therefore, the estimation of knowledge structures as "correct" or "wrong" is defined by cultural norms and attitudes in society.

The propensity of anthropomorphism in modern research into animal behavior leads to the appearance of articles in serious scientific journals in which author states that elephants are capable of understanding death (McComb, Baker, \& Moss, 2006), and the cognitive intellect of crows and ravens equals that of a chimpanzee (Seed, Emery, \& Clayton, 2009). This is not surprising. If in classical psychology, knowledge was the impartial logical-conceptual analysis of reality, for nonclassical psychology, knowledge began to represent an episystem (knowledge coordinated with internal canons of the rational analysis of a reality), and in postnonclassical psychology, when the world is weighed by values, a new ideology of rationality, humanistic anthropomorphism, is created.

All these testify that the old traditional opposition of the world "in itself" and the person mastering and reformatting this world leaves the stage, giving the person the possibility to realize its inclusiveness in the cognizable world and dependences on it, i.e., the ontological paradigm of knowledge enters into psychology.

In the postnonclassical conception of reality the dichotomy between internal and external reality is removed, modern methodology starts to pay more attention to features of communications which, according to Habermas (2003), are the intermediary between the person and the world.

Barabanshchikov (2005) and Panov (2004), being supporters of an ontological paradigm in psychology, asserted that it is necessary to consider the unity of the individual and environment when the world simultaneously includes the individual and resists him. Without the world analysis (its components, structure, norms, and rules to which it submits, dynamics, etc.), it is impossible to characterize the subject (as an agent of his own acts) and forms of his activity (Barabanshchikov, 2005).

But then, the motivation of human behavior (and, possibly, behavior of vertebrates at least from the reptile level in which individual life experience plays the serious role) is a subjective determination of human or animal behavior by the world. Only through such motivation does the individual appear included in the context of reality. The value of objects and phenomena and their sense for the individual determine its behavior in the world.

With displacement of a subject of psychology from rational consciousness to direct experience in the process of interaction with the world, the psychological method also changes. Therefore, modern psychologists speak of "an understanding method" more frequently. According to Dielthey (1996), elementary understanding occurs directly, it is an understood expression of feeling. In the process of interaction, the individual wants to understand what is expected of him by other individuals. Another sign of elementary understanding, according to Dielthey (1996), is concrete sights, gestures, and behavior that are understood as expressions of internal and sensual experience. This appears true not only concerning human society, but also concerning animals 
(Gardenfors, 2003), and human-animal interaction (Nikolskaya, 2010). According to Edmund Husserl, we understand others by analogy to us, i.e., as managing their bodies and understanding through experience the same world that is understood by us. In turn, we understand animals as "abnormal modifications" of ourselves (Gusserl, 1998).

Any reality of living beings is their vital world, senses of objects or situations surrounding them, and their purpose in the given situational context. These vital worlds are difficult to describe by quantitative indicators, the qualitative characteristics of these vital worlds are required here.

Certainly, it is difficult to reproduce the data and results of qualitative research, therefore, the possibility of obtaining universal scientific conclusions is in doubt. But in a postnonclassical stage of scientific development, the question about truth and the meaning of knowledge as mentioned above, shifts to the context of "communicative rationality" (Habermas, 2003) and the area of communication.

Thus, methods of understanding can and should be content with probabilities, as truth is an ideal, but probability is a reality.

In connection with the methodological bases of postnonclassical psychology described above, it is put forward a theoretical model of human-animal relationships offering possible methodology and methods of research in the field of undirected pet therapy.

(1) The person obtaining a pet forms a heterospecific group with it, which is understood as the person and an animal united by joint ability to live with each other and occupy joint territory, having psychological contact with each other, mutual emotional relationships, and specific rules of behavior in relation to each other;

(2) The necessary condition for creation of a heterospecific group is the presence of need by both parties in such an interaction. Occurrence of such a need in animals is caused by the human who has created an environment for domestic animals that is distinct from the habitat of their wild relatives, and this artificial environment forces the animal to seek contact with humans in order to survive.

The same need in humans is more differentiated and lies in the field of satisfaction of a requirement for unification with nature, or in the field of personal or environmental deficit. In cases where an animal is obtained for a child suffering from some form or another of dysontogenesis, it is possible to speak of an environmental deficit, i.e., the parents try to find a way to help improve the condition of the child;

(3) Thus, the animal can be perceived by the owner: (a) as an object (in the case of pet therapy as a tool for treating the child); (b) as another person (when the animal "is humanized" by the owner, and the owner expects it to carry out the functions of a human child, friend, etc.; and (c) as a living being of other species possessing needs, emotions, individual and specific characteristics, and so forth. Depending on the perception of the animal, the person builds different relationships with it. Then we come to three types of heterospecific relations: the subject (person)—object (animal) (Type 1); the subject (person)— the subject (an animal as another person) (Type 2); and the subject (person) - the subject (animal) (Type 3);

(4) In the process of human-animal interaction, the psychological phenomena of trust, attachment, and rules established in a heterospecific group and methods of communication arise;

(5) The owner's trust in the pet is the mental formation of a person, expressing the person's relation to the animal depending upon the perception of the animals following characteristics: its reliability, i.e., the degree to which it justifies the owner's expectations, predictability, and how safe the animal is considered to be. The factor supporting the balance in a heterospecific group is the psychological phenomenon of trust. This 
phenomenon arises in every type of heterospecific interaction;

(6) Usually, the love (attachment) of the person for the animal (a Type 2 interaction) is based on a symbiotic union in which each party cannot do without the other (the animal owing to its vulnerability without the person, and the person owing to the personal or environmental deficit which for which it uses the animal to compensate). But another form of human love for a pet is possible, which includes such elements as care, knowledge of the animal, respect for its needs, and belief in its abilities. Then the love acts as the statement of life of another and develops both human and animal (interaction of three types).

In order to create a sense of attachment in an animal, a human must care for it. But care that does not give the animal the possibility to mature does not allow for the animal's mature, reciprocal attachment to the human. To achieve the mature reciprocal relationship, the person should make the animal's habitat as rich as possible. The animal must learn as much as it can, and be able to cope with the situations it faces. For example, a human's mature love for an animal promotes the animal's development;

(7) A sufficient condition for an interspecific group to exist is the ability of its members to develop and adopt norms of interaction. Norms of interaction in each heterospecific group can be different (for example, the owner can allow the animal to sleep in his bed or not, or the animal can allow the owner to touch it while it is sleeping or not). The main thing is that these norms of behavior are mutually observed;

(8) There is a certain formal sequence of actions by the partners, in which in reply to any action, the participant in communications expects a reciprocal action from the partner in the process of heterospecific communication. The choice of actions is determined by situational context, relationship history and the established rules, and norms of interaction.

That such communications have arisen, the animal should: (a) have a need for such communication; and (b) exist in an enriched environment in which reasonable use of communication suggests that some benefit will be achieved.

Hence, the more difficult and more differentiated communicative system between participants in interaction promotes greater mutual development. If the person as the subject of heterospecific interaction is attuned to subjective relations with an animal, seeing simply an animal rather than an idealized image or substitute social partner, then the communicative repertoire of the participants will be more varied;

(9) The dynamics for creating a functioning heterospecific group include the following: Members of a heterospecific group must have a need for interaction (the first stage), the person starts to build up interaction with the animal depending on his perception of the animal as an object, or as a subject substitute for personal relations, or as an independent live subject (the second stage). Depending on the type of interaction, the mental phenomena influencing the process of interaction arise in the heterospecific group (the third stage). We have presented an ontological view of conditions, determinants, and phenomena of occurrence and existence of heterospecific human/pet groups;

(10) Then, the methods most relevant to research of heterospecific groups and correction of infringements in these groups will be as follows:

(a) The supervisory method allows observation of the nonverbal signals between the person and animal in the course of interaction, and the owner's ability to understand and consider the animal's needs. The adviser observes the owners' nonverbal behavior in the course of conversation and the behavior of an animal in the office and in the course of "acquaintance" with the adviser. This offers the opportunity to gather preliminary 
empirical data regarding interaction between the animal and its owner;

(b) The method of conversation is directed toward revealing stories of heterospecific groups and problems in a group. In the course of conversation, it is important to determine that the researcher has understood the client correctly, because it is easy to misinterpret the client's words. It is important to summarize your understanding of the client's comments and solicit his affirmation that you have interpreted his words correctly. Upon termination of this stage, the researcher should have 2-3 hypotheses regarding the problems that have arisen in the given interspecific group;

(c) The method of constructing a grounded theory (Strauss, 1984). This method allows us in each case to classify the deviation from the interspecific phenomenon within a particular interspecies group;

(d) The functional test method is applied in the event that during research, the adviser must confirm or deny the hypothesis in "field" conditions (out of office). Certain aspects of nonverbal behavior by participants in heterospecific groups and their interaction outside the office environment offer the researcher additional information, and also confirm or deny the hypothesis regarding the "source" of the problem, which can be either the person or the animal;

(e) At last, correction of infringement for the purpose of restoring stability in the group is, as a matter of fact, an experimental method since the researcher's external influence on the group leads to those or other changes and, hence, allows conclusions regarding stability and types of interaction;

(11) For a diagnostic basis, the following classification has been accepted: (a) infringements from the animal; and (b) infringements from the person.

In case of Type 1 infringements (from the animal), the mental state and adaptive behavioral patterns of the animal come to light. The basic information includes facts reported by the animal's owner as well as what we note ourselves while observing the interaction between animal and human. In the course of interviews with owners, we received information on the animal's early life, its current environment, including family structure and the animal's relationship with each family member. The final questions concern features of the animal's behavior, which cause anxiety for the owner.

In case of Type 2 infringements (from the person), the adviser should generate a hypothesis regarding the desires and fears in interpersonal relations that the client is transferring to the relationship with the animal.

Moreover, the adviser should explain the core of the problem to the owner, including specific behaviors exhibited by the animal, and suggest ways of changing their own behavior toward the animal to address the problem. Ideally, the advice should contribute to improved interaction in the heterospecific group, and finally, improve the family atmosphere, and in turn, promote an improvement in the emotional state of the child.

\section{References}

Barabanshchikov, V. A. (2005). Methods of psychological knowledge: A system view (Yaroslavl methodological seminar works). Methods of Psychology, 3, 14-23.

Dielthey, W. (1996). Descriptive psychology. Aleteya: S. Petersburg.

Frith, U. (Ed.). (1991). Autism and asperger syndrom. N. Y.: Cambridge University Press.

Gardenfors, P. (2003). Slicing the theory of mind. Retrieved from http://www.lucs.lu.se/people/Peter.Gardenfors//articles/slicing TOM.html

Grandgeorge, M. (2011). Hausberger. Annali Dell'Istituto Superiore di Sanita, 47(4), 397-408.

Gusserl, E. (1989). Ideas pertaining to a pure phenomenology and to a phenomenological philosophy—Second book: Studies in the phenomenology of constitution. Kluwer Academic Publishers. 
Habermas, J. (1987). The philosophical discourse of modernity. Cambridge: Massachusetts Institute of Technology Press.

Horwitz, D., \& Mills, D. (2009). BSAVA manual of canine and feline behavioural medicine (2nd ed.). BSAVA.

Lebedev, S. A. (2010). Modern philosophy of science. Moscow, Voronezsh: MPSI, MODEK.

McComb, K., Baker, L., \& Moss, C. (2006). African elephants show high levels of interest in the skulls and ivory of their own species. Biology Letters, 2, 26-28.

Millon, T. (1981). Disorders of personality. Wiley, N. Y.: DSM-III-Axis II.

Nikolskaya, A. V. (2007). Diagnosis and correction of abnormal behaviour in dogs. Moscow: Aquarium-Print.

Nikolskaya, A. V. (2010). Animal psychology and interspecific psychology. Moscow: Exmo.

Overall, K. (2005). Clinical behavioral: Medicine for small animals. Philadelphia: University of Pennsylvania Press.

Panov, V. I. (2004). Ecological psychology. Moscow: Nauka.

Rothenmerg, M. (1977). Children with emerald eyes: Histories of extraordinary boys and girls. N. Y.: Dial Press.

Seed, A. M., Emery, N. J., \& Clayton, N. S. (2009). Intelligence in corvids and apes: A case of convergent evolution? Ethology, $115,401-420$

Strauss, A. L. (1984). Qualitative analysis in social research: Grounded theory methodology. Hagen: Study Letter, University Hagen.

Temple, G. (1988). Behaviour of slaughter plant and auction employees toward animals. Anthrozoos, 4, 205-213. 